\title{
Bimetallic Au-Pt nanoparticles synthesized by radiolysis: Application in electro-catalysis
}

\author{
Malaknaz Mirdamadi-Esfahani, ${ }^{1}$ Mehran Mostafavi, ${ }^{1}$ Bineta Keita, ${ }^{1}$ Louis Nadjo, ${ }^{1}$ \\ Patricia Kooyman, ${ }^{2}$ Hynd Remita ${ }^{*}$ \\ www.goldbulletin.org
}

\begin{abstract}
$2 \mathrm{~nm}$ bimetallic alloyed Au-Pt nanoparticles were synthesized via electron beam irradiation. The nanoparticles were characterized using TEM and EDAX analysis, and tested as electrocatalysts for different fuel-cell related reactions. Our results show that these Au-Pt nanoparticles are promising for application in fuel cells.
\end{abstract}

\section{Introduction}

Bimetallic nanoparticles (NPs) attract sustained attention due to their application in catalysis and electrocatalysis. In particular, bimetallic platinumbased catalysts have been proposed as promising alternatives to the exceedingly expensive pure $\mathrm{Pt}$ electrocatalysts and are already widely used in industry and for proton exchange membrane (PEM) fuel cells. ${ }^{1,2}$ Among numerous possible metal combinations, Au-Pt NPs have been studied intensively because of their optical properties, ${ }^{3}$ their potential as selective oxidation $n^{4,5}$ and dehydrogenation catalysts, ${ }^{6}$ electrocatalysts, ${ }^{7,8,9}$ and selective sensors. Cationic Au-Pt clusters have shown unique reactivity for $\mathrm{C}-\mathrm{N}$ coupling of methane and ammonia. ${ }^{11,12}$ Recently it has been reported that carbon-supported Au-Pt bimetallic NPs display performances better or similar to those of pure platinum supported on carbon for oxygen reduction, ${ }^{13,14}$ provided alloyed and not phasesegregated Au-Pt NPs are used. It has been also shown that platinum could be partially substituted by gold for application in methanol oxidation: higher resistance to poisoning was observed in acidic media with Au-Pt bimetallic NPs, while in alkaline environment a significant overall improvement in performance was reported. ${ }^{14}$ The main remaining challenge is that the preparation of alloyed Au-Pt NPs either requires severe thermal treatments, generally yielding aggregated particles, or follows milder but complicated routes to obtain nanostructured materials. ${ }^{15,16}$ Typically, these milder procedures involve the use of dendrimer complexes ${ }^{15}$ or phase transfer agents and encapsulating agents together with thermal treatment in the latter case. ${ }^{16}$ The microemulsion and the impregnation routes proved effective, in contrast to the colloidal procedure. $^{13}$ Organometallic or coordination complex precursors could also be used with the drawback of pre-imposed Pt-to-Au atomic stoichiometry. 4,17
Laboratoire de Chimie Physique, Bât. 349-350, UMR 8000CNRS, Université Paris-Sud 11, F- 91405 Orsay Cedex, France DelftChemTech and National Centre for HREM, Delft University The Netherlands

*Corresponding author: hynd.remita@u-psud.fr

Keywords: gold, platinum, bimetallic nanoparticles, radiolysis, fuel cells, hydrogen production, methanol oxidation 
In this context, it is assumed that radiolytic reduction might provide a convenient route to synthesize alloyed Au-Pt NPs exhibiting desired physicochemical properties. Radiolytic reduction of metal ions in solution is an efficient process to synthesize bimetallic nanoparticles of controlled size and structure. ${ }^{18,19,20}$ Different bimetallic nanoparticles have been synthesized by this technique as either core-shell particles or alloys, depending on the dose rate, such as: Au-Ag, ${ }^{21} \mathrm{Au}-\mathrm{Pd},{ }^{22,23} \mathrm{Au}-\mathrm{Pt}^{, 24} \mathrm{Ag}-\mathrm{Pd}^{25} \ldots$ The hydrated electrons and the reducing radicals produced during the radiolysis of the solvent are used to reduce metal ions.

Here, we report on the radiolytic one-step synthesis of bimetallic alloyed Au-Pt NPs and their behaviour in selected test reactions. Assessment of the electrocatalytic activity of the radiolytically synthesized Au-Pt NPs shows that they exhibit a high efficiency for methanol oxidation in alkaline medium and for proton reduction.

\section{Experimental section}

\section{Chemicals:}

Metal salts $\mathrm{KAuCl}_{4}$ (Degussa, purity $\geq 99.8$ ) and/or $\mathrm{H}_{2} \mathrm{PtCl}_{6}$ (Aldrich, purity $\geq 99.8$ ) were dissolved (metal concentration $1 \times 10^{-3}-2 \times 10^{-3} \mathrm{~mol} \mathrm{~L}^{-1}$ ) in an aqueous solution containing $0.1 \mathrm{M}$ polyacrylic acid (Aldrich, average $\mathrm{MW}=2000$ ) and $0.2 \mathrm{M}$ 2-propanol (Prolabo) (as $\mathrm{OH}^{\prime}$ 'scavenger to enhance the radiolytic yield). ${ }^{18}$

\section{Irradiations:}

The solutions containing the metal complexes were put in small pyrex flasks and were deoxygenated by bubbling with nitrogen before irradiation. Electron beam irradiations were performed with a $20 \mathrm{~kW}$ and 10 MeV electron accelerator (LEONI Studer Hard Society, Switzerland).

\section{Characterization techniques:}

UV-vis spectra were recorded with a Varian DMS $100 \mathrm{~S}$ spectrophotometer.

TEM was performed on nanoparticles deposited on carbon-coated copper grids using a JEOL JEM 100 CXII transmission electron microscope at accelerating voltage of $100 \mathrm{kV}$ or with a FEI Tecnai equipped with a FEG operating at 200 kV. EDX elemental analysis was performed using an Oxford Instruments system. The copper signal in the EDX spectra is due to background radiation hitting the Cu TEM grid.
Electrochemical experiments:

The source, mounting and polishing of the glassy carbon (GC, Le Carbone Lorraine, France) electrodes for the electrochemical experiments have been described previously, ${ }^{26}$ as was the fabrication technique of the modified electrodes. ${ }^{27}$ The glassy carbon samples had a diameter of $3 \mathrm{~mm}$. The electrochemical set-up was an EG \& G 273 A driven by a PC with the M270 software. Potentials are quoted against a saturated calomel electrode (SCE) or a $\mathrm{Hg} / \mathrm{HgO}$ (1 $\mathrm{M} \mathrm{KOH}$ ) reference electrode. The counter electrode was a platinum gauze of large surface area. Pure water was used throughout. It was obtained by purification through a RiOs 8 unit followed by a Millipore-Q Academic purification set. The solutions were de-aerated thoroughly for at least 30 minutes with pure argon and kept under a positive pressure of this gas during the experiments. The

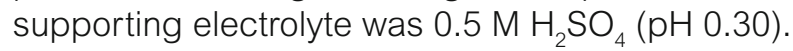

\section{Result and discussion}

\section{Au-Pt nanoparticle synthesis}

The UV-visible spectrum of $\mathrm{Au}(\mathrm{III}) / \mathrm{Pt}(\mathrm{IV})$ mixed solution, before the electron beam irradiation, exhibits a shoulder at $325 \mathrm{~nm}$ due to $\mathrm{Au}^{\prime \prime \prime} \mathrm{Cl}_{4}$ complexes and an intense absorption at $260 \mathrm{~nm}$ due to the $\mathrm{Pt}^{\mathrm{IV}} \mathrm{Cl}_{6}{ }_{6}^{2-}$ complexes (Figure 1, inset). The UV-visible spectrum of the solution irradiated with a 12 kGy dose is shown Figure 1. No plasmon band of pure gold is observed and the spectrum is close to that obtained with pure platinum as shown in Figure 1. TEM shows that the NPs are homogeneous in size and have diameters of 2-3 nm (Figure 2, bottom). Energy dispersive X-ray (EDX) analysis attests that the NPs are composed of Au and Pt (Figure 2, top). Previous experiments have shown that radiolysis of a solution containing $\mathrm{PtCl}_{4}{ }^{2-}$ and $\mathrm{AuCl}_{4}{ }^{-}$leads to formation of $\mathrm{Au}_{\text {core }}-\mathrm{Pt}_{\text {shell }}$ NPs of typical diameter 3-4 $\mathrm{nm}$ at low dose rate (by $\gamma$-irradiation), or to alloyed Au-Pt nanoparticles of typical diameter 2-3 nm at high dose rate (electron beam irradiation). ${ }^{24}$ This difference in the NP structure is due to electron transfer from $\mathrm{Pt}$ complexes or nascent $\mathrm{Pt}^{0}$ induced by radiolysis to gold complexes ( $\mathrm{Au}^{\prime \prime \prime}$ or $\mathrm{Au}$ ) occurring only at low dose rate when the reduction kinetics is slow. At high dose rate, the reduction of all ions can be achieved rapidly before any intermetallic electron transfer can occur, leading to alloyed nanoparticles. Indeed, different experiments have already confirmed the alloyed structure of the Au-Pt nanoparticles synthesized by electron beams (UV-Vis, selected energy X-ray spectroscopy (EDS), selected area electron diffraction (SAED)). ${ }^{24}$ 


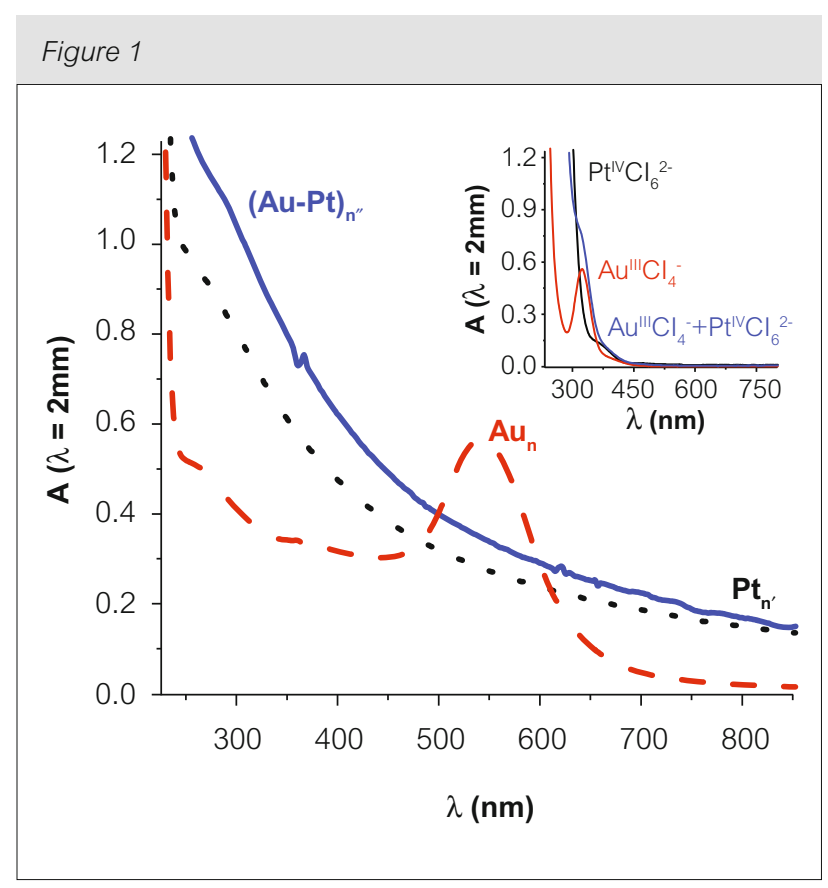

UV-vis spectra of solutions containing $\left[\mathrm{PtCl}_{6}^{2-}\right]=5 \times 10^{-4} \mathrm{~mol}$. $\mathrm{L}^{-1}$ and/or $\left[\mathrm{AuCl}_{4}^{-}\right]=5 \times 10^{-4} \mathrm{~mol} \cdot \mathrm{L}^{-1},[\mathrm{PAA}]=0.1 \mathrm{~mol} \cdot \mathrm{L}^{-1}$ and [2-propanol] $=0.1 \mathrm{~mol} . \mathrm{L}^{-1}$ irradiated by electron beam (------),

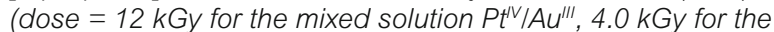
solution containing Pt'V or $\left.A u^{\prime \prime \prime}\right)$. Insert: Absorption spectra before irradiation of the solutions containing Au (III) complexes (------), Pt (IV) complexes (------) and Au (III) / Pt (IV) complexes (----). (As reference, the plasmon band of Pt NPs (---) and Au NPS $(--)$ in the pure state are also reported)

\section{Characterization of the electrode modified with Au-Pt nanoparticles}

The bimetallic Au-Pt NPs were deposited on a glassy carbon electrode for preliminary electrochemical evaluations in acidic and in alkaline media. The cyclic voltammograms run with this electrode in $0.5 \mathrm{M} \mathrm{H}_{2} \mathrm{SO}_{4}$ or $1 \mathrm{M} \mathrm{KOH}$, respectively, display the characteristic features of both metals (see Fig. 3 and Fig. 4).

The voltammetric patterns observed for pure Au and pure Pt in sulfuric acid are well-established. ${ }^{28}$ Starting the potential scan from zero toward the positive potential direction, Figure 3 shows the formation of Pt and Au oxides (peak I). On potential reversal, we successively observe the reduction of Au oxides (peak II), of Pt oxides (peak III), then the adsorption of hydrogen and its evolution (peaks IV and $V$ ) in the negative potential domain, followed by hydrogen oxidation and desorption on the final potential scan back to zero. This pattern gathers the characteristics of the two metals, but, in comparison with pure metals, a shift in the negative potential direction is observed for reduction of the oxides
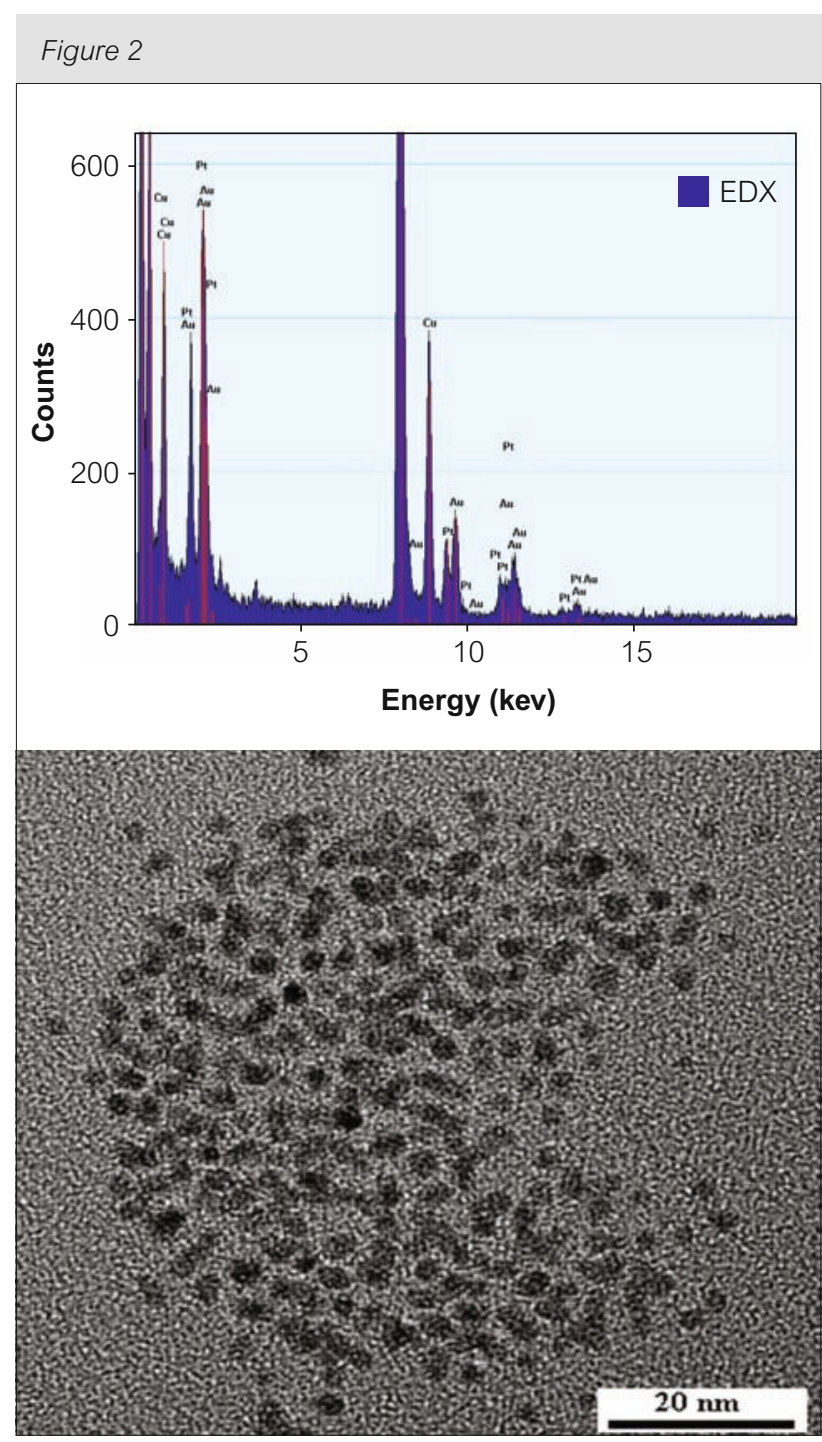

TEM micrograph and the corresponding EDX signal of AulPt particles obtained after total reduction (dose $=12 \mathrm{kGy}$ ) by electron beam irradiation of a solution containing $\left[\mathrm{PtCl}_{6}^{2-}\right]=$ $5 \times 10^{-4} \mathrm{~mol} . \mathrm{L}^{-1},\left[\mathrm{AuCl}_{4}^{-}\right]=5 \times 10^{-4} \mathrm{~mol} . \mathrm{L}^{-1},[\mathrm{PAA}]=0.1 \mathrm{~mol}^{\circ} \mathrm{L}^{-1}$ and $\left[2\right.$-propanol] $=0.1 \mathrm{~mol} . \mathrm{L}^{-1}$

of both metals. The pattern does not change upon repeated cycling.

Figure 4 shows a set of CVs obtained as a function of potential scan rate in $1 \mathrm{M} \mathrm{KOH}$ with a glassy carbon electrode modified with electron beam synthesized Au-Pt alloyed NPs. By comparison ${ }^{29}$ with the patterns observed with pure monometallic catalysts in the same medium, peak I features the oxidation of the two metals, peaks II and III the reduction of $\mathrm{Au}$ oxides, Pt oxides and peak IV and its counterpart the sorption-desorption pattern of hydrogen. Here again, the presence of the two metals is clearly detected. 


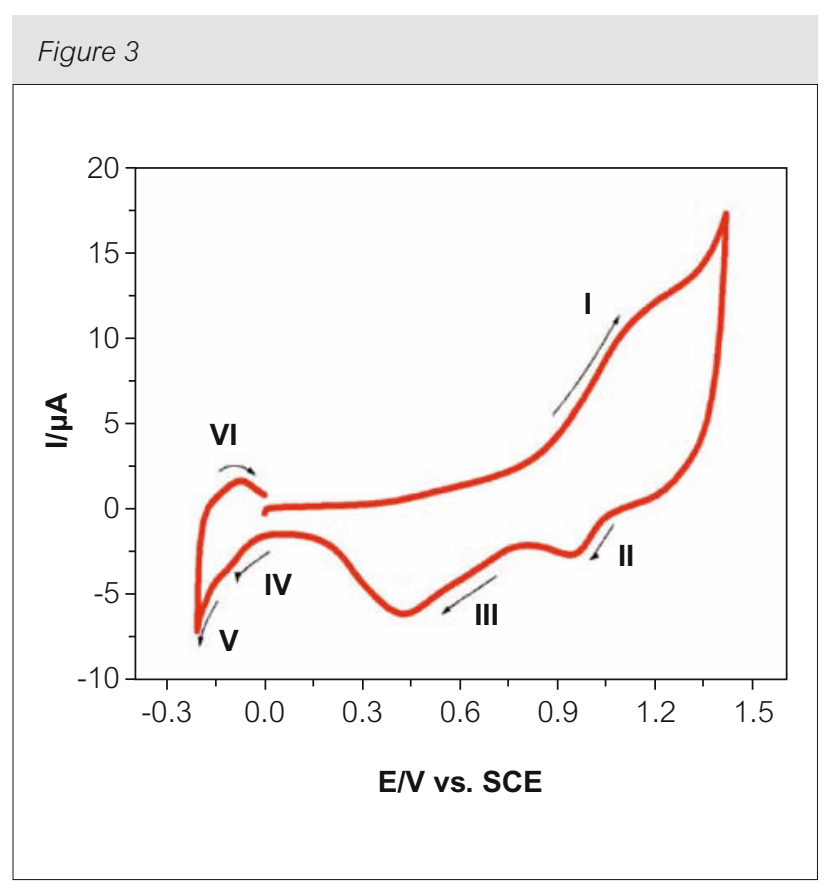

Cyclic voltammogram run in $0.5 \mathrm{H}_{2} \mathrm{SO}_{4}$ with a glassy carbon electrode modified with electron beam synthesized Au-Pt alloyed NPs. The potential scan rate was $10 \mathrm{mV} \mathrm{s}^{-1}$. The reference electrode was a $\mathrm{KCl}$-saturated calomel electrode (SCE) and the counter electrode a platinum gauze of large surface area. The solution was deoxygenated by pure argon

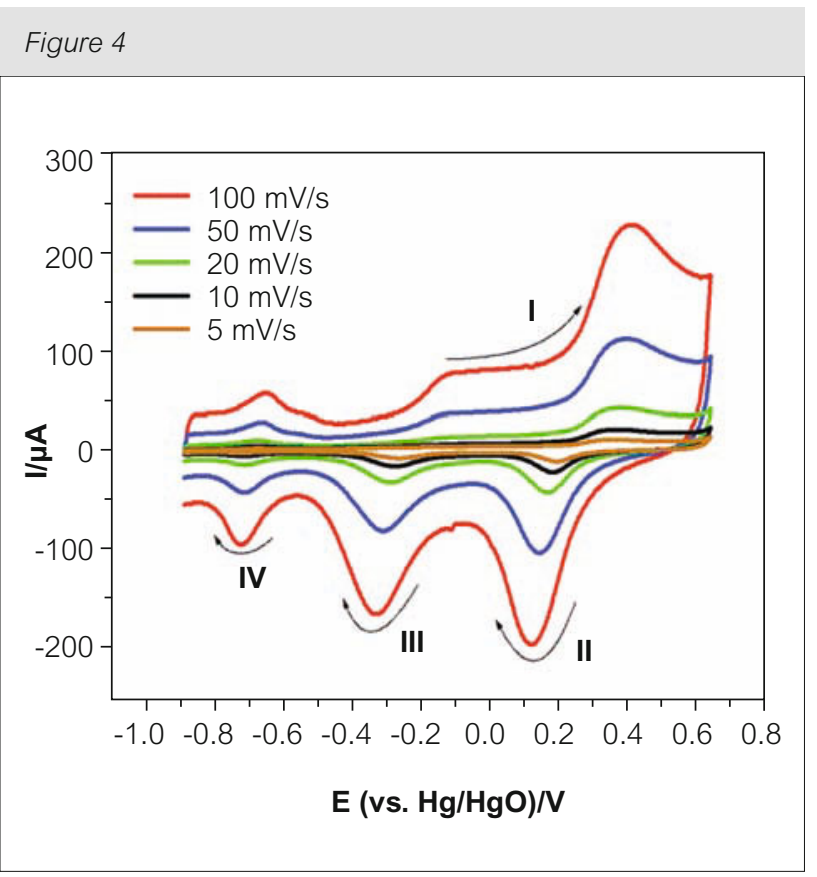

Cyclic voltammograms run in $1 \mathrm{M} \mathrm{KOH}$ with a glassy carbon electrode modified with electron beam synthesized Au-Pt alloyed NPs. The solution was deoxygenated by pure argon. The reference electrode was a $\mathrm{Hg} / \mathrm{HgO}(1 \mathrm{M} \mathrm{KOH})$ reference electrode and the counter electrode a platinum gauze of large surface area

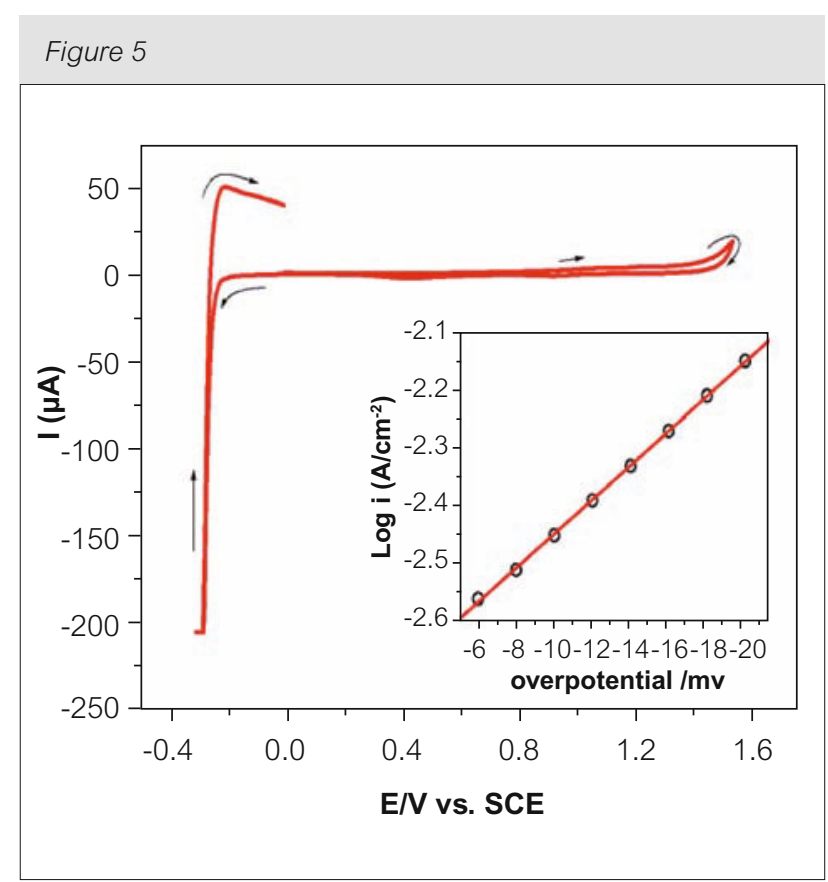

Cyclic voltammogram run in $0.5 \mathrm{M} \mathrm{H}_{2} \mathrm{SO}_{4}(\mathrm{pH}=0.3)$ with a glassy carbon electrode modified by Au-Pt nanoparticles (50:50) in the absence of oxygen. The potential scan rate was $2 \mathrm{mV} \mathrm{s}^{-1}$. The reference electrode was a $\mathrm{KCl}$ saturated calomel electrode (SCE) and the counter electrode a platinum gauze of large surface area. Inset: Tafel analysis of the hydrogen evolution reaction

\section{The hydrogen evolution reaction}

In $0.5 \mathrm{M} \mathrm{H}_{2} \mathrm{SO}_{4}$, the electrode, modified by Au-Pt NPs, shows a remarkable activity for the hydrogen evolution reaction. The corresponding pattern, obtained at a scan rate of $2 \mathrm{mV} \mathrm{s}^{-1}$, is displayed in Figure 5 along with its Tafel analysis. The Tafel slope is $-34 \mathrm{mV} /$ decade and the exchange current density, determined using the electrode geometric surface area, is $\log \left(i_{0}, A_{c m}^{-2}\right)=-2.74 \pm 0.02$. The exchange current density should be considered as an estimate because the real electrode surface area was unknown. Even so, our results indicate a remarkable activation of the glassy carbon electrode, with characteristics close to those of $\mathrm{Pt}$ electrodes, for which $\log \left(\mathrm{i}_{0}, \mathrm{~A} \mathrm{~cm}^{-2}\right)=-3.34$ to -2.63 , with slopes ranging from -30 to $-120 \mathrm{mV} /$ decade. ${ }^{30}$ Summarizing, a pure Pt-like behavior is observed for the hydrogen evolution reaction (HER).

\section{The methanol oxidation reaction in alkaline medium}

The role of the two components of the present alloy is more clear when studying the $\mathrm{MeOH}$ oxidation reaction (MOR) in $1 \mathrm{M} \mathrm{KOH}$ using an electrode modified with the Au-Pt NPs. Figure 6 displays the cyclic voltammograms obtained in $1 \mathrm{M} \mathrm{KOH}$ with 


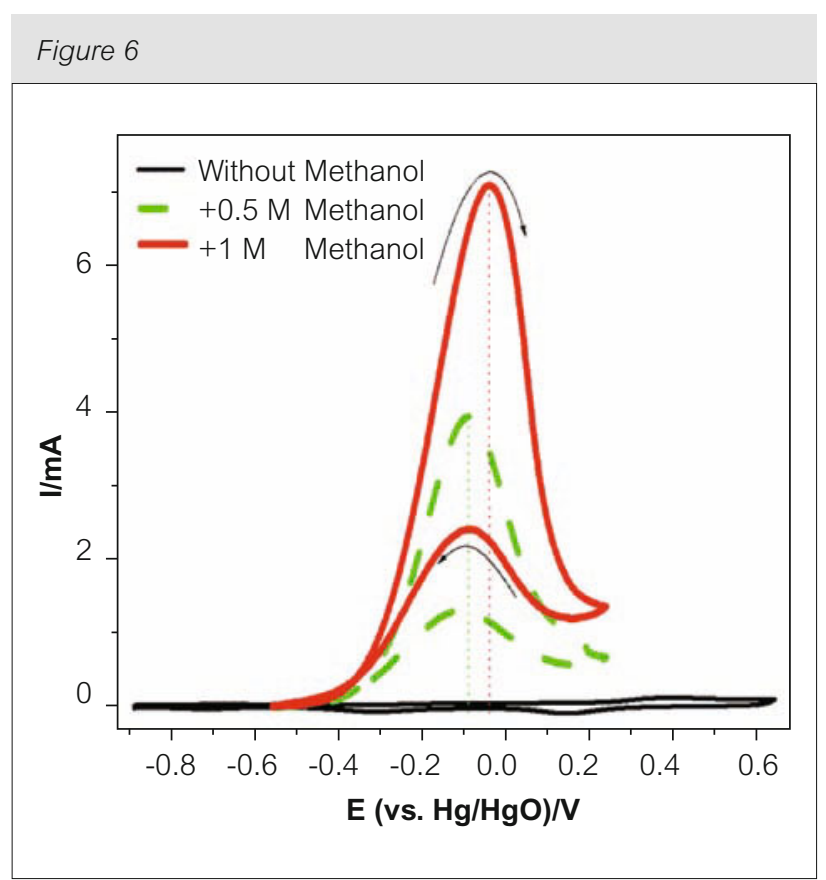

Cyclic voltammograms run with an Au-Pt (50:50)-modified electrode in $1 \mathrm{M} \mathrm{KOH}$ without $\mathrm{MeOH}(-)$ or containing $0.5 \mathrm{M} \mathrm{MeOH}$ (- - - ) or $1 \mathrm{M} \mathrm{MeOH} \mathrm{(-}-$ ). The solution was deoxygenated by argon bubbling. The potential scan rate was $50 \mathrm{mV} \mathrm{s}^{-1}$. The reference electrode was a $\mathrm{Hg} / \mathrm{HgO}(1 \mathrm{M} \mathrm{KOH})$ reference electrode and the counter electrode a platinum gauze of large surface area

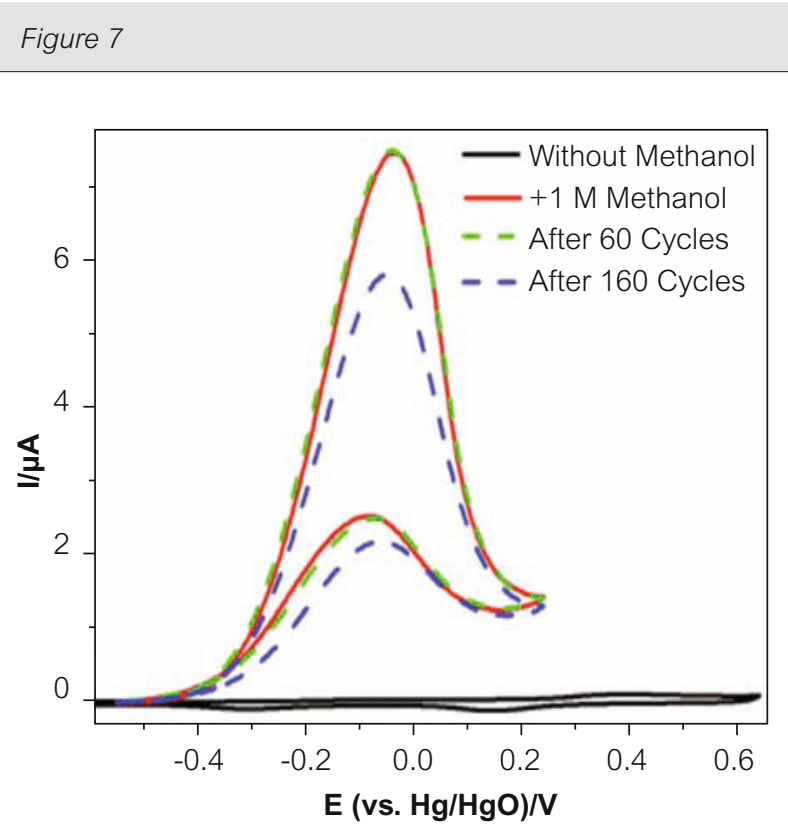

Comparison of the 1st, 60th and 160th cyclic voltammograms observed during the electrocatalytic oxidation of $1 \mathrm{M} \mathrm{MeOH}$ in $1 \mathrm{M} \mathrm{KOH}$ with an Au-Pt (50:50)-modified electrode. The solution was deoxygenated. The potential scan rate was $50 \mathrm{mV} \mathrm{s}^{-1}$. The reference electrode was a $\mathrm{Hg} / \mathrm{HgO}(1 \mathrm{M} \mathrm{KOH})$ reference electrode and the counter electrode a platinum gauze of large surface area
$0.5 \mathrm{M}$ and $1 \mathrm{M} \mathrm{MeOH}$, respectively at a scan rate of $50 \mathrm{mV} \mathrm{s}^{-1}$. For both concentrations, a single wave is observed during the forward scan and another smaller single wave is obtained on the reverse scan. In addition, only small differences exist between the peak potential locations of the forward and the reverse waves. Such behaviors are different from those of pure Pt or pure Au NPs in alkaline medium and probably reflect a cooperative bimetallic effect of the Au-Pt NPs on the MOR. Table 1 gathers the main literature cyclic voltammetry characteristics for pure Au nanoparticles supported on carbon $(\mathrm{Au} / \mathrm{C})$, pure $\mathrm{Pt} / \mathrm{C}$, Au-Pt nanoparticles synthesized using various procedures and also those of the present work. Even though disparity in experimental conditions precludes quantitative comparisons, two trends emerge: i) the characteristics measured in the present work with $0.5 \mathrm{M} \mathrm{MeOH}$ in alkaline medium comply with literature values; ${ }^{31,32}$ ii) the potential characteristics for the cyclic voltammograms, including the faradaic current onset potential $\left(E_{\text {onset }}\right)$, the forward peak potential $\left(E_{f}\right)$ and the backward peak potential $\left(E_{b}\right)$ are smaller for Au$\mathrm{Pt}$ than the corresponding values for pure $\mathrm{Au}$ or pure Pt. Analysis of the particle suspension gives: for Pt $(1.91 \pm 0.01) \mathrm{mg} / \mathrm{mL}$ and for Au (2.09 \pm 0.01$)$ $\mathrm{mg} / \mathrm{mL}$. The mass activity calculated for the CV of Figure $6(1 \mathrm{M} \mathrm{MeOH}$ in $1 \mathrm{M} \mathrm{KOH})$ gives 0.295 $\mathrm{A} /(\mathrm{mg}$ of total amount of metal) which compares very favorably with the value of $0.300 \mathrm{~A} /(\mathrm{mg}$ of total amount of metal) estimated from data published by $\mathrm{Xu}$ et al. ${ }^{33}$ Finally, the durability of the modified electrodes was studied by cyclic voltammetry and by chronoamperometry. Figure 7 shows a superposition of the CVs corresponding to the first, the 60th and the 160th runs. Perfect stability was observed at least up to the 60th scan. Actually, in this experiment a current decrease, due to electrode poisoning by adsorption of $\mathrm{CO}$ and/or anions, is observed beyond the 100th cycle. For chronoamperometry, the potential was stepped from $-0.550 \mathrm{~V}$ to $0.25 \mathrm{~V}$ and maintained at this last value for 1000 seconds (Figure 8). After this duration, $15.4 \%$ of the initial current remains left. The corresponding value estimated for pure Pt NPs supported on carbon gives $8.8 \% .{ }^{33}$ This comparison establishes the better durability of the present Au-Pt NPs over pure Pt NPs. Altogether, these observations indicate that electron beam irradiation constitutes a valuable one-step route for the synthesis of $\mathrm{Au}-\mathrm{Pt}$ alloyed NPs, with behaviors comparable to those of NPs obtained by more complicated methods. This preliminary result will stimulate our search for the optimal compositions of Au-Pt NPs and the study of their applications. 
Table 1. Voltammetry characteristics for $\mathrm{MeOH}$ oxidation in a solution containing: a: $1 \mathrm{M} \mathrm{NaOH}+1 \mathrm{M} \mathrm{MeOH}$; b: $0.5 \mathrm{M} \mathrm{KOH}+0.5 \mathrm{M}$ de $\mathrm{MeOH}$; c: $1 \mathrm{M} \mathrm{KOH}+0.5 \mathrm{M} \mathrm{MeOH}$; d: $1 \mathrm{M} \mathrm{KOH}+1 \mathrm{M} \mathrm{MeOH}$

\begin{tabular}{|c|c|c|c|c|c|c|c|c|}
\hline $\mathbf{N}$ & Catalyst & ${ }^{1} M_{1}: M_{2}$ & $\begin{array}{c}{ }^{2} \mathrm{E}_{\text {onset }} \\
\mathrm{mV} \text { vs. } \\
\mathrm{Ag} / \mathrm{AgCl}\end{array}$ & $\begin{array}{c}{ }^{3} \mathrm{E}_{\mathrm{f}} \\
\mathrm{mV} \text { vs. } \\
\mathrm{Ag} / \mathrm{AgCl}\end{array}$ & $\begin{array}{c}{ }^{4} \mathrm{E}_{\mathrm{b}} \\
\mathrm{mV} \text { vs. } \\
\mathrm{Ag} / \mathrm{AgCl}\end{array}$ & $\mathrm{mA} / \mathrm{cm}^{2}$ & ${ }^{5} I_{f} / I_{b}$ & Ref. \\
\hline 1 & ${ }^{\mathrm{a} A u}$ & $100: 00$ & +1 & +410 & +410 & 0.3 & 1.09 & 34 \\
\hline 2 & ${ }^{\mathrm{b}} \mathrm{Pt}^{6}$ & $00: 100$ & -462 & -180 & -390 & 7.14 & 7 & 29 \\
\hline 3 & ${ }^{\mathrm{b}} \mathrm{Au} / \mathrm{Pt}$ & $35: 65$ & -455 & -180 & -200 & 6.14 & 7 & 31 \\
\hline 4 & ${ }^{\mathrm{b}} \mathrm{Au} / \mathrm{Pt}$ & $68: 32$ & -370.4 & -136 & -127 & 8.57 & 12 & 29 \\
\hline 5 & ${ }^{\mathrm{b}} \mathrm{Au} / \mathrm{Pt}$ & $72: 28$ & -455 & -190 & -195 & 6.86 & 10 & 31 \\
\hline 6 & ${ }^{\mathrm{b}} \mathrm{Au} / \mathrm{Pt}$ & $81: 19$ & -371.4 & -131 & -137 & 2.66 & 3 & 29 \\
\hline 7 & ${ }^{\mathrm{b}} \mathrm{Au} / \mathrm{Pt}^{7}$ & $82: 18$ & -450 & -170 & -215 & $\begin{array}{l}\text { A) } 5 \\
\text { B) } 6.7\end{array}$ & $\begin{array}{l}\text { A) } 8 \\
\text { B) } 7.5\end{array}$ & 32 \\
\hline 8 & ${ }^{\mathrm{c}} \mathrm{Au} / \mathrm{Pt}$ & $53: 47$ & -450 & -170 & -190 & 56.14 & 3 & This work \\
\hline 9 & ${ }^{\mathrm{d}} \mathrm{Au} / \mathrm{Pt}$ & $53: 47$ & -450 & -126.5 & -175.5 & 101.28 & 3 & This work \\
\hline \multicolumn{9}{|c|}{$\begin{array}{l}{ }^{1} M_{1}: M_{2}: \text { atomic ratio of } A u \text { and } P t \text { in } A u-P t \\
{ }^{2} E_{\text {onset }}: \text { faradaic current onset potential } \\
{ }^{3} E_{f}: \text { forward peak potential } \\
{ }^{4} E_{b}: \text { backward peak potential } \\
{ }^{5} I_{f}: \text { forward peak current intensity, } I_{b}: \text { backward peak current intensity } \\
{ }^{6} P t: \text { commercially available }(E-t e k) \text {. } \\
{ }^{7} \text { Note: currents vary with the treatment temperature of catalysts }\left(A: 400^{\circ} \mathrm{C} ; B: 500^{\circ} \mathrm{C}\right)\end{array}$} \\
\hline
\end{tabular}

Figure 8

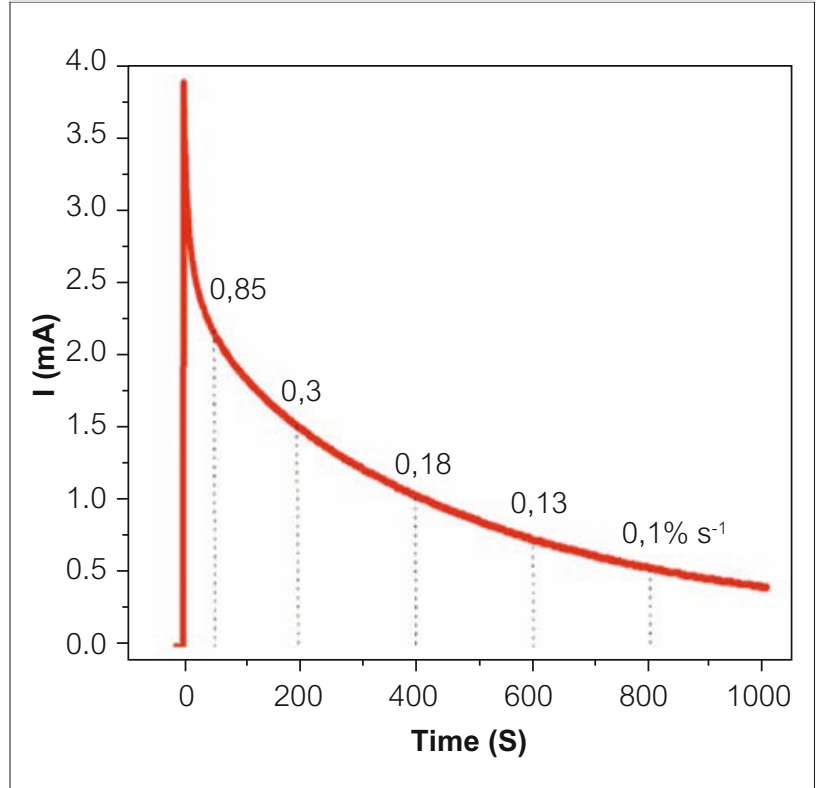

Chronoamperogram observed during the electrocatalytic oxidation of $1 \mathrm{M} \mathrm{MeOH}$ in $1 \mathrm{M} \mathrm{KOH}$ with an Au-Pt (50:50)modified electrode. The solution was deoxygenated. The initial potential was fixed at $-0.55 \mathrm{~V}$, stepped to $0.25 \mathrm{~V}$ and held there. The reference electrode was a $\mathrm{Hg} / \mathrm{HgO}(1 \mathrm{M} \mathrm{KOH})$ reference electrode and the counter electrode a platinum gauze of large surface area. The numbers on the curve indicate the current decrease percentage as a function of time

\section{Conclusion}

Electron beam radiolytic reduction of mixed Aull'/Pt'v aqueous solutions leads to 2-3 $\mathrm{nm}$ bimetallic nanoparticles. It features a simple, onestep, procedure to synthesize true alloys. These nanoparticles are promising for application in fuel cells. Work in progress will look for the optimum composition range of the Au-Pt nanoparticles for use in various applications including electrocatalytic processes.

\section{Acknowledgements}

The authors acknowledge Conrad Günthard from LEONI Studer Hard Society for electron-beam irradiation. This work was supported by the CNRS and the University Paris-Sud 11(UMR 8000). The authors acknowledge financial support from the European Union under the framework 6 program under the contract for an Integrated Infrastructure Initiative, reference 026019 ESTEEM. 


\section{About the authors}
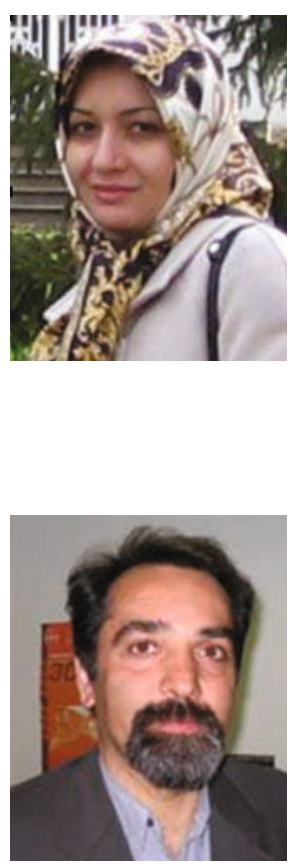

Malaknaz Mirdamadi Esfahani received in 2009 her $\mathrm{PhD}$ degree in Physical Chemistry from the Université Paris-Sud under the supervision of Professor Mehran Mostafavi. She has presently a post-doctoral position at the Nano-Biotechnology Laboratory of the University Shahid Beheshti in Tehran. She is working on photonic and electrochemical biosensors based on nanomaterials.

Mehran Mostafavi is Professor of Physical Chemistry at Paris-Sud University and the head of the Laboratoire de Chimie Physique of CNRS at Orsay. One of his research interests is the mechanism of metal and semiconductor nano-clusters growth induced by irradiation in solution.

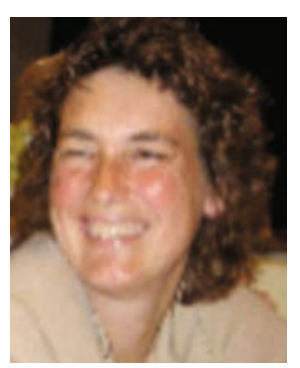

Patricia J. Kooyman is assistant Professor in Catalysis Engineering at Delft University of Technology since 2002. Her activities are focused on structure-activity relations in heterogeneous catalysts (zeolites and mesoporous materials, sulphides, metal nanoparticles) and include state-of-the art transmission electron microscopy.

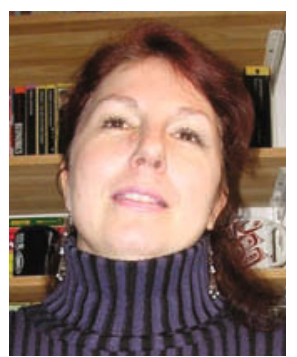

Hynd Remita is a CNRS researcher since 1994. She is working in the Laboratoire de Chimie Physique in Orsay at the Paris-Sud University. Her research interests focus on radiolysis, metal nanoparticles and nanomaterials, nucleation and growth processes, fuel cells and photocatalysis.

Dr Bineta Keita (Directeur de Recherche in the French CNRS) and Professor Louis Nadjo are senior researchers. Their work is focused on electrochemistry and electrocatalysis.

\section{References}

1 A.S. Arico, S. Srinavasan, V. Antonucci, Fuel cells 2001, 1, 133

2 C. Lamy, E.M. Belgsir and J.M. Léger, J. Appl. Electrochem. 2001, 31, 799

3 T. Shiraishi, K. Hisatsune, Y. Tanaka, E. Miura, Y. Takuma, Gold Bull. 2001, 34, 129

4 C. Mihut, C. Descorme, D. Duprez, M.D. Amiridis, J. Catal. 2003, 212, 125

5 A. Vazquez-Zavala, J. Garcia-Gomez, A. Gomez-Cortes, Appl. Surf. Sci. 2000, 167, 177

6 J. Shen, J.M. Hill, M.W. Ramachandra, S.G. Podkolzin, J.A. Dumesic, Catal. Lett. 1999, 60, 1

7 Y. Lou, M.M. Maye, L. Han, J. Luo, C.J. Zhong, Chem. Commun. 2001, 5, 473

8 M.M. Maye, N.N. Kariuki, J. Luo, L. Han, P. Njoki, L. Wang, Y. Lin, H. Naslund, C.J. Zhong, Gold Bulletin 2004, 37, 217

9 J. Luo, M.M. Maye, N.N. Kariuki, L. Wang, P. Njoki, Y. Lin, M. Schadt, H.R. Naslund, C.J. Zhong, Catalysis Today 2005, 99, 291

10 D.C. Skelton, H. Wang, R.G. Tobin, D.K. Lambert, C.L. Dimaggio, G.B. Fisher, J. Phys. Chem. B 2001, 105, 204

11 K. Koszinowski, D. Schroder, H. Schwartz, Organometallics 2004, 23, 1132

12 K. Koszinowski, D. Schroder, H. Schwartz, Angew. Chem., Int. Ed. 2004, 43, 121

13 P. Hernandez-Fernandez, S. Rojas, P. Ocon, J.L. Gomez de la Fuente, J. San Fabian, J. Sanza, M.A. Pena, F.J. GarciaGarcia, P. Terreros, J.L.G. Fierro, J. Phys. Chem. C, 2007, 111, 2913

14 W. Tang, S. Jayaraman, F.T. Jaramillo, G.D. Stucky, E.W. McFarland, J. Phys. Chem. C 2009, 113, 5024

15 H. Lang, S. Maldonado, K.J. Stevenson, B.D. Chandler, J. Am. Chem. Soc. 2004, 126, 12949

16 J. Luo, M.M. Maye, V. Petkov, N.N. Kariuki, L. Wang, P. Njoki, D. Mott, Y. Lin, C.J. Zhong, Chem. Mater. 2005, 17, 3086

17 B.D. Chandler, A.B. Schabel, C.F. Banford, L.H. Pignolet, J. Catal. 1999, 187, 367

18 J. Belloni, M. Mostafavi, H. Remita, J.L. Marignier, M.O. Delcourt, New.J.Chem., 1998, 22, 1239

19 J. Belloni, Catal. Today, 2006, 113, 141

20 J. Belloni, H. Remita, "Metal clusters and nanomaterials" in "Radiation Chemistry: From basics to applications in material and life sciences", Ed. M. Spotheim-Maurizot, M. Mostafavi, T. Douki, and J. Belloni, EDP Sciences, 2008, p. $97-116$

21 M. Tréguer, C. de Cointet, H. Remita, J. Khatouri, M. Mostafavi, J. Amblard, J. Belloni, R. De Keyser, J. Phys. Chem. B, 1998, 102, 4310

22 H. Remita, A. Etcheberry, J. Belloni, J. Phys. Chem. B, 2003, 107, 31

23 F. Ksar, L. Ramos, B. Keita, L. Nadjo, P. Beaunier, H. Remita, Chem. Mater. 2009, 21, 3677 
24 H. Remita, I. Lampre, M. Mostafavi, S. Bouffard, Radiat. Phys. Chem., 2005, 72, 575

25 H. Remita, J. Khatouri, M. Tréguer, J. Amblard, J. Belloni, Z. Phys. D, 1997, 40, 127

26 B. Keita, L. Nadjo, J. Electroanal. Chem., 1988, 243, 87

27 B. Keita, G. Zhang, A. Dolbecq, P. Mialane, F. Sécheresse, F. Miserque, L. Nadjo, J. Phys. Chem.C, 2007, 111, 8145

28 M.N. Desic, M.M. Popovic, M.D. Obradovic, L.M. Vracar, B.N. Grgur, J. Serb. Chem. Soc. 2005, 70, 231

29 J. Luo, M.M. Maye, N.N. Kariuki, L. Wang, P. Njoki, Y. Lin, M. Schadt, H.R. Naslund, C.J. Zhong, Catal. Today 2005, 99, 291

30 a) S. Trasatti, J. Electroanal. Chem. 1972, 39, 163-184.; b) J. Norskov, T. Bligaard, A. Logadottir, J.R. Kitchin, J.G. Chen, S. Pandelov, U. Stimming, J. Electrochem. Soc., 2005, 152, 323; c) M. Enyo, B.E. Conway, J.O'M. Bockris, in E. Yeager, S.V.M. Khan, R.E. White (Eds), Comprehensive Treatise of Electrochemistry, Vol. 7, Plenum Press, New York, 1983, p. 241
31 D. Mott, J. Luo, P.N. Njoki, Y. Lin, L. Wang, C.J. Zhong, Catalysis Today 2007, 122, 378

32 J. Luo, P.N. Njoki, Y. Lin, D. Mott, L. Wang, C.J. Zhong, Langmuir 2006, 22, 2892

33 C. Xu, L. Cheng, P. Shen, Y. Liu, Electrochem. Commun. 2007, 9, 997

34 J. Hernandez, J. Solla-Gullon, E. Herrero, A. Aldaz, J.M. Feliu, Electrochimica Acta 2006, 52, 1662 